\title{
Overexpression of caspase-3 in hepatocellular carcinomas
}

\author{
Rajendra Persad ${ }^{1}$, Chen Liu ${ }^{1}$, Tsung-Teh Wu ${ }^{1}$, Patrick S Houlihan ${ }^{1}$, Stanley R Hamilton ${ }^{1}$, \\ Anna M Diehl ${ }^{2}$ and Asif Rashid ${ }^{1}$ \\ ${ }^{1}$ Department of Pathology, The University of Texas, MD Anderson Cancer Center, Houston, TX, USA and \\ ${ }^{2}$ Department of Medicine, Johns Hopkins University, Baltimore, MD, USA
}

\begin{abstract}
Caspase-3 is a downstream effector cysteine protease in the apoptotic pathway. It is ubiquitously expressed in normal human tissues including the liver. Overexpression and loss of expression of caspase-3 has been reported in diverse human malignancies. However, expression of caspase-3 in hepatocellular carcinoma (HCC) has not been studied. Therefore, we studied its expression in four hepatoma cell lines and 22 HCCs by Western blot, and correlated the findings with in vitro caspase-3 activity and apoptosis. In addition, 47 surgically resected HCCs and 29 metastatic colorectal carcinomas were evaluated for caspase-3 expression by immunohistochemistry on formalin-fixed, paraffin-embedded tissue sections, and the staining intensity was correlated with the clinicopathological features. Caspase-3 overexpression was present in all four hepatoma cell lines, and $68 \%(15 / 22)$ of HCCs in comparison to the non-neoplastic liver parenchyma by Western blot, and in $52 \%(36 / 69)$ of HCCs by immunohistochemistry. Caspase-3 overexpression in HCCs by Western blot correlated with caspase-3 overexpression by immunohistochemistry $(P=0.002)$, and in vitro caspase-3 activity $(P=0.01)$. Caspase-3 overexpression in HCCs by immunohistochemistry was associated with serum $\alpha$ fetoprotein (AFP) levels $(P=0.01)$. In conclusion, caspase-3 is frequently overexpressed in HCCs and is associated with high serum levels of AFP.

Modern Pathology (2004) 17, 861-867, advance online publication, 16 April 2004; doi:10.1038/modpathol.3800146
\end{abstract}

Keywords: caspase-3; hepatocellular carcinomas; overexpression; $\alpha$-fetoprotein

Apoptosis is a selective, controlled, and genetically programmed cell death process that occurs as a result of normal cellular differentiation and development. Defects in apoptosis contribute to many diseases, including cancer, autoimmune and neurodegenerative disorders. This process is mediated by a complex mechanism involving intracellular proteases, the caspases, and activators and inhibitors of these cell death proteases (reviewed in $\operatorname{Reed}^{1}$ ). Apoptosis is characterized morphologically by cell shrinkage, cytoplasmic membrane blebbing, nuclear fragmentation and condensation, and internucleosomal DNA cleavage. In liver, apoptosis plays a prominent part in the pathogenesis of toxic liver injury due to a variety of agents, viral hepatitis, and hepatocellular carcinomas (HCCs) (reviewed in Kanzler and Galle ${ }^{2}$ ).

Correspondence: Dr A Rashid MD, PhD, Department of Pathology, Box 85, The University of Texas, MD Anderson Cancer Center, 1515 Holcombe Boulevard, Houston, TX 77030-4095, USA.

E-mail: arashid@mdanderson.org

Received 11 February 2004; revised and accepted 25 March 2004; published online 16 April 2004
Apoptosis is initiated by binding of Fas ligand (FasL, CD95L) to Fas, tumor necrosis factor (TNF) to TNF receptors 1 and 2 , transforming growth factor $\beta$ (TGF $\beta$ ) to TGF $\beta$ receptors, or TNF-related apoptosisinducing ligand (TRAIL) to its receptors. ${ }^{1,2}$ Fas and TNF receptor 1 attach to cytosolic adaptor proteins (FADD, MORT, RIP, TRADD), which in turn recruit caspase-8 to activate caspase-3. Caspase-3 (also known as CPP32, YAMA, and apopain), a cysteine protease, is related to interleukin- $1 \beta$-converting enzyme and is the human homologue of nematode Caenorhabditis elegans Ced-3..$^{3,4}$ Caspase- 3 gene has been localized to chromosome 4q33-35.1., ${ }^{5,6}$ The active form of caspase- 3 is generated after proteolytic cleavage of the procaspase-3 at specific aspartic acid residues to generate two subunits with molecular mass of 17 and $12 \mathrm{kDa}$. The two subunits associate with each other to form active caspase- 3 complex. Caspase-3 is ubiquitously expressed in human tissue including liver and in human cell lines. ${ }^{3,7}$ Overexpression and loss of expression of caspase-3 has been reported in a variety of human cell lines and malignancies. ${ }^{8-18}$

Expression of caspase-3 in HCC has not been studied in detail. ${ }^{19}$ Therefore, we studied its 
expression in HCCs and associations with the clinicopathological features. We also studied the overexpression of caspase-3 in hepatic metastases of colorectal adenocarcinomas for comparison. In the present study, we examined overexpression of caspase-3 by immunohistochemistry, immunoblot and functional activity in HCC and adjoining liver parenchyma, and compared overexpression status with patient and tumor characteristics.

\section{Materials and methods}

\section{Cell Culture}

SK-Hep 1, PLC-5, Hep G2, and Hep 3B HCC cell lines and SW-480 colon carcinoma cell line were obtained (American Type Culture Collection, Manassas, VA, USA). All cell lines were maintained at a subconfluent state in MEM containing $10 \%$ FCS, $200 \mathrm{U} / \mathrm{ml}$ penicillin, and $200 \mu \mathrm{g} / \mathrm{ml}$ streptomycin in a humidified atmosphere of $5 \% \mathrm{CO}_{2}$ at $37^{\circ} \mathrm{C}$. Hep $3 \mathrm{~B}$ and SW-480 were supplemented with $2 \mathrm{mM}$ L-glutamine.

\section{Characteristics of Patients and Specimens}

Fresh frozen non-neoplastic liver and HCC tissue was obtained from 22 patients who underwent surgical resction for HCC at The Johns Hopkins Hospital, Baltimore. ${ }^{20}$ Tissues from patients were collected after surgical removal, immediately snapfrozen in liquid nitrogen, and stored at $-80^{\circ} \mathrm{C}$. A representative section was thawed and fixed in $10 \%$ formalin for 1 day at room temprature, processed, and embedded in paraffin. In addition, formalinfixed, paraffin-embedded tissue was also obtained from resection specimens of 47 patients with HCC and 29 patients with hepatic metastasis of colorectal cancers at the MD Anderson Cancer Center, Houston who underwent curative resection. The clinicopathological factors were evaluated by review of surgical pathology reports and patients' charts, and tumor survival was obtained from the tumor registry. This study was approved by the Institutional Review Board of the MD Anderson Cancer Center.

\section{Cell and Tissue Lysate and Western Blot}

Subconfluent cultures of the cell lines were collected by centrifugation in a clinical centrifuge at $1000 \mathrm{rpm}$ for $10 \mathrm{~min}$. The pellet was washed twice with PBS. The cell lines, non-neoplastic liver and HCC tissues were lysed by adding $400 \mu \mathrm{l}$ of lysate buffer comprising of $20 \mathrm{mM}$ Na phosphate buffer $\mathrm{pH}$ 7.4, $1 \%$ Triton X-100, $150 \mathrm{mM} \mathrm{NaCl,} 5 \mathrm{mM}$ EDTA to $100 \mu \mathrm{l}$ of cell pellet or tissue samples. The lysate was left on ice for $30 \mathrm{~min}$, vortexed and centrifuged for $15 \mathrm{~s}$. The supernatant was collected and stored at $-80^{\circ} \mathrm{C}$ until further use. The protein was quantiated by measuring against known quantity of BSA by measuring optical density at $A_{595}$. Protein $(20 \mu \mathrm{g})$ was electrophoresed on $15 \%$ polyacrylamide gel and transferred to nylon membrane (BioRad, Hercules, CA, USA). The membrane was probed with anti-caspase-3 antibody at 1:1000 dilution (PharMingen, San Diego, CA, USA). The membrane was developed using Lumiglo kit (New England Biolabs, Beverly, MA, USA). Representative samples were reprobed with a mouse anti- $\beta$-actin antibody (Sigma, St Louis, MO, USA) to control for equal loading of protein. Band intensities were measured by densitometry. Lysates from cell lines and tumor tissue with caspase-3 band densities at least twice the band densities of normal liver parenchyma were classified as overexpression.

\section{Caspase-3 Immunohistochemistry}

Immunohistochemistry for caspase-3 was performed on formalin-fixed, paraffin-embeded tissue, ${ }^{7}$ on 69 HCCs, including 22 HCCs evaluated for Western blot and 47 surgically resected HCCs, and 29 hepatic metastasis of colorectal cancers from MD Anderson Cancer Center. Sections ( $5 \mu \mathrm{m}$ thick) on positively charged slides were deparaffinized in xylene, hydrated in graded alcohol, and pretreated for antigen retrieval in $10 \mathrm{mmol} / \mathrm{l}$ citrate buffer, $\mathrm{pH}$ 6.0 , in a steamer at $98^{\circ} \mathrm{C}$ for $45 \mathrm{~min}$. Staining was performed using polyclonal rabbit anti-caspase-3 antibody (1:1000 dilution, PharMingen, San Diego, CA, USA), DAKO EnVision systems (DAKO Corporation, Carpinteria, CA, USA), and chromogen 3,3'-diaminobenzidine tetrahydrochloride. The staining intensity of the HCCs and hepatic metastasis of the colorectal cancers were compared with that of adjacent non-neoplastic hepatic parenchyma by semiquantitative visual evaluations by two observers (RP and AR). Overexpression was considered to be present when the intensity of tumor staining was at least twice the staining intensity of adjacent non-neoplastic liver.

\section{Caspase-3 Assay}

Caspase-3 activity was assessed by using a commercial kit according to the manufacturer's instructions (ApoAlert Caspase Fluorescent Assay Kits, CLONTECH Laboratories Inc., Palo Alto, CA, USA). Briefly, $20 \mu \mathrm{g}$ of cell culture or tissue lysates was added to equal volume of reaction buffer containing $10 \mathrm{mM}$ DTT and $5 \mu \mathrm{l}$ of $1 \mathrm{mM}$ caspase- 3 substrate (DEVD-AMC). The reaction was incubated at $37^{\circ} \mathrm{C}$ for $1 \mathrm{~h}$. A negative control without lysate was used in all experiments. Caspase-3 inhibitor $(1 \mu \mathrm{l})$ (DEVDCHO), a specific inhibitor of caspase-3, was used to show specificity of caspase-3 activity. The activity was below background levels after the addition of caspase-3 inhibitor. These experiments were performed in triplicate and repeated twice. 


\section{In Situ Apoptosis by TdT-mediated dUTP Nick End Labeling}

Apoptosis was measured by TdT-mediated dUTP nick end labeling (TUNEL) assay in paraffinembedded sections using a commercial kit (In situ cell death detection kit, Roche Diagnostics $\mathrm{GmbH}$, Mannheim, Germany) according to the manufacturer's instructions as previously described. ${ }^{21}$ Briefly, $5 \mu \mathrm{m}$ thick sections of formalin-fixed, parrafin-embeded tissue was deparrafinized by heating the slides at $60^{\circ} \mathrm{C}$, washing in xylene, and rehydrating through a graded series of ethanol and distilled $\mathrm{H}_{2} \mathrm{O}$. The tissue section was incubated with $20 \mu \mathrm{g} /$ $\mathrm{ml}$ proteinase $\mathrm{K}$ in $10 \mathrm{mM}$ Tris/HCl, $\mathrm{pH} 7.4$ for $30 \mathrm{~min}$ at $37^{\circ} \mathrm{C}$. The slides were washed twice with phosphate-buffered saline. The tissue was incubated with $50 \mu \mathrm{l}$ of solution containing terminal deoxynucleotidyl transferase, buffer and fluorescein-labelled nucleotides in a humidified chamber for $60 \mathrm{~min}$ at $37^{\circ} \mathrm{C}$ in the dark. Sections of lymph nodes were used as positive control for apoptosis. The slides were washed thrice with phosphate-buffered saline. The slides were analyzed under a fluorescence microscope and apoptotic cells were counted in five high power fields $\left(1 \mathrm{~mm}^{2}\right)$.

\section{Statistical Analysis}

$\chi^{2}$ or Fisher's exact tests were performed for comparison of frequency of each clinical or pathological characteristic. T-test was used for comparison of means. Correlation between caspase-3 activity and TUNEL assay was evaluated by means of Spearman's rank correlation coefficient. Overall survival time was determined from the date of surgery and compared using the product-limit method. ${ }^{22}$

\section{Results}

Overexpression of Caspase-3 by Immunoblot and Caspase-3 Immunohistochemistry

Western blot analysis was performed using lysates prepared from SK-Hep1, PLC-5, Hep G2, Hep 3B and SW-480 cell lines, and non-neoplastic liver and tumor tissue from 22 patients with HCC. All four HCC cell lines, and all tumor and non-neoplastic samples had a band of $M_{\mathrm{r}} \sim 32000$ consistent with procaspase- 3 . The caspase- 3 band was more intense by 2-3-fold in lysates from SK-Hep1, PLC-5, Hep G2, and Hep 3B HCC cell lines compared to SW-480 colon carcinoma cell lines (Figure 1a). $\beta$-Actin band was of similar intensity in all samples showing equal loading of samples. Similarly, 2-3-fold more intense caspase-3 expression was present in $68 \%$ $(15 / 22)$ of lysates from HCC in comparison to the lysates from non-neoplastic liver parenchyma or the remaining seven HCC lysates (Figure 1b). However, a band of $M_{\mathrm{r}} 17000$, a subunit of caspase-3 present after caspase-3 activation, was absent from all lysates indicating lack of caspase-3 activation (data not shown).

All non-neoplastic liver parenchyma and HCCs expressed caspase-3 by immunohistochemistry (Figure 2). Caspase-3 overexpression was assessed by immunohistochemistry in 69 HCCs, including 22 with lysates, and 29 hepatic metastasis of colorectal cancers. The staining intensity for caspase-3 was similar to the adjoining non-neoplastic liver parenchyma in $33(48 \%)$ HCCs; but the remaining 36 $(52 \%)$ carcinomas overexpressed caspase-3 relative to the non-neoplastic liver parenchyma. In contrast, none of 29 metastatic colonic adenocarcinomas overexpressed caspase-3.

The caspase-3 overexpression in lysates from HCC correlated with overexpression by immunohistochemistry: 14 HCC had overexpression by both methods, one had overexpression by Western blot only, two had overexpression by immunohistochemistry only, and the remaining five had no overexpression by either method $(P=0.002)$.

\section{In Vitro Caspase-3 Activity and TUNEL Assay}

The in vitro caspase-3 activity was measured using the lysates from cell lines, and non-neoplastic liver and HCC tissue. PLC5 had increased caspase-3 activity, Hep3B had reduced activity, and the other three cell lines had intermediate activity (Figures 3 and 4). The caspase-3 activity levels were similar in 22 non-neoplastic liver (mean 1495 \pm 2557 ) and seven HCC without caspase-3 overexpression (mean $1676 \pm 1990)$ but were increased in HCC with caspase-3 overexpression (mean 6290 \pm 6503 ; $P=0.01$ vs non-neoplastic liver, and $P=0.02$ vs HCC without caspase-3 overexpression). Similarly, the caspase-3 activity levels were increased in HCC cell lysates (mean 5005 \pm 4054 ) vs non-neoplastic liver $(P=0.03)$.

TUNEL assay had increased apoptosis in HCC with caspase-3 overexpression but was not statistically significant (Figure 4). HCC without caspase-3 overexpression had $5.4 \pm 5.5$ apoptotic lesions in five high-power fields compared to $13.8 \pm 14.1$ in HCC with caspase-3 overexpression $(P=0.06)$. There was a weak correlation between caspase-3 activity and apoptosis in HCCs $(r=0.431, P=0.045$, Figure 4).

\section{Overexpression of Caspase-3 and Association with Clinicopathological Features}

Overexpression of caspase-3 was associated with serum $\alpha$-fetoprotein (AFP) levels in patients with HCCs (Table 1 and Figure 5). Serum AFP > $>40$ IU was present in three of $10(30 \%)$ HCCs without caspase-3 overexpression and 16 of 21 (76\%) HCCs with caspase-3 overexpression $(P=0.01)$. Caspase-3 

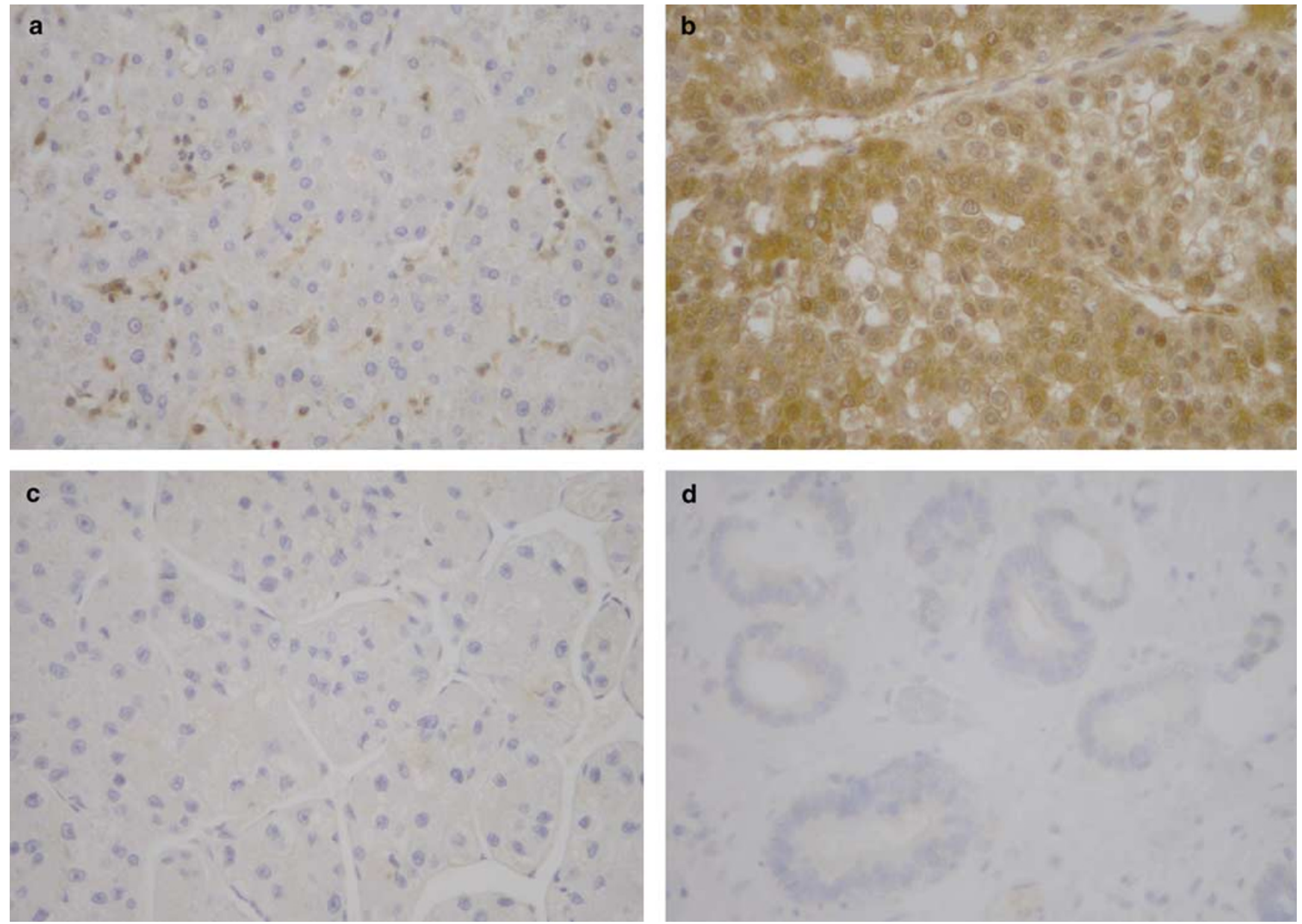

Figure 1 Expression of caspase-3 by immunohistochemistry. (a) Adjacent normal liver parenchyma, (b) HCC with caspase-3 overexpression, (c) HCC without caspase-3 overexpression, and (d) colon carcinoma metastatic to colon.

a

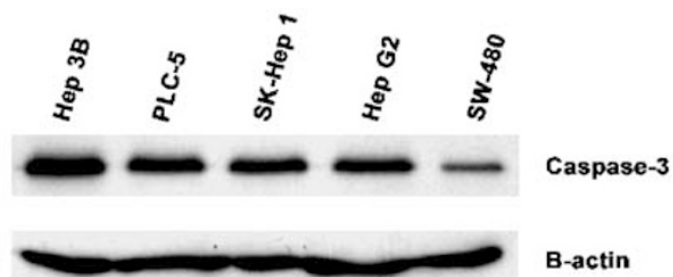

b

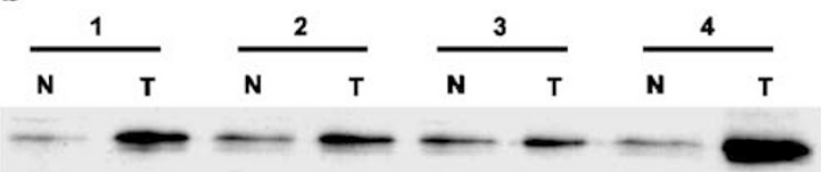

Figure 2 Western blot analysis of caspase-3 protein expression in (a) human hepatocellular and colon cancer cell lines, and (b) HCC and adjoining liver tissue from patients with HCC. Cell lysates were prepared from the cell lines and subjected to PAGE $(15 \%)$ and blotted to nylon membrane. All HCC cell lines Hep 3B, PLC5, SK-Hep 1, and HepG2 overexpress caspase-3 compared to colon carcinoma cell line SW-480. Similarly, HCC samples 1T, 2T, and $4 \mathrm{~T}$ overexpress caspase-3 compared to non-neoplastic liver samples N1-5 or HCC sample 3T.

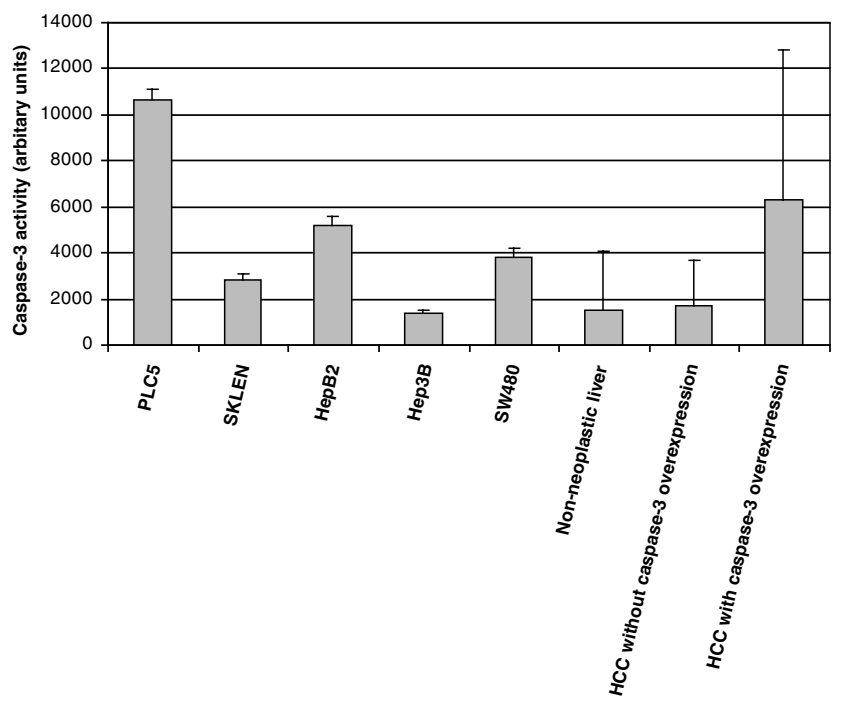

Figure 3 Mean \pm s.d. of caspase-3 activity in hepatocellular and colon cancer cell lines, and normal liver and tumor tissue from patients with HCC. HCCs with caspase-3 overexpression and HCC cell lines had increase caspase-3 activity. 


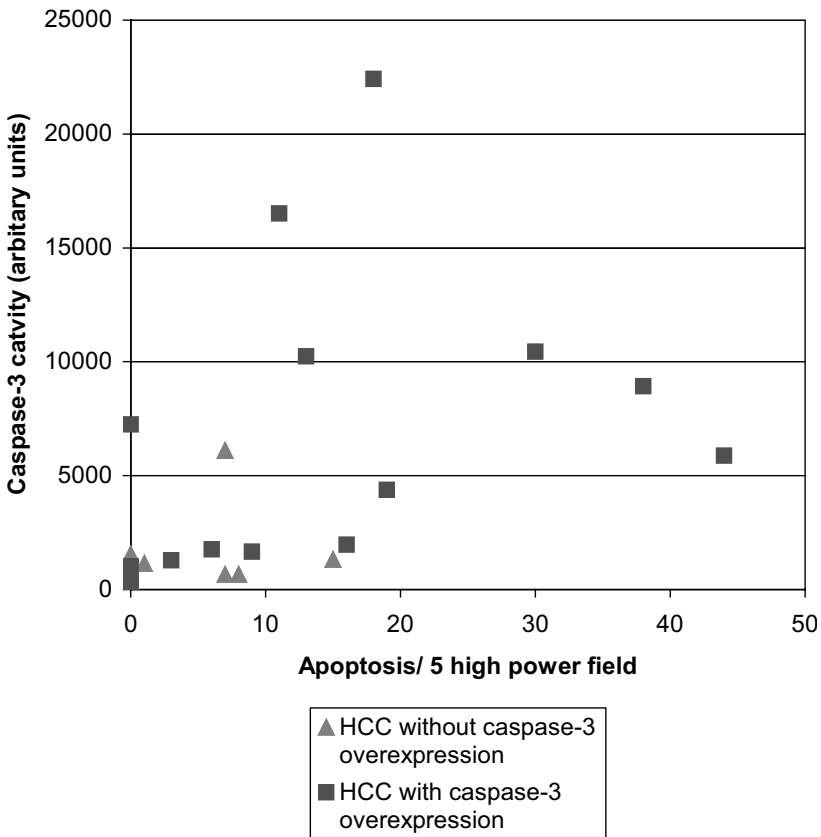

Figure 4 Caspase-3 activity and apoptosis in HCCs with and without caspase-3 overexpression by Western blot.

overexpression did not correlate with other clinicopathological features or patient survival.

\section{Discussion}

In our study, caspase-3 was overexpressed in all four HCC cell lines and a subset of HCCs compared to nontumor liver tissue using immunoblot and immunohistochemistry. In contrast, a previous report had reported reduced expression of caspase-3 by immunohistochemistry in HCCs compared to nontumor liver tissue. ${ }^{19}$ These differences may be due to differences in methodology including use of different primary antibodies. Caspase-3 overexpression and reduced expression have been reported in diverse types of malignant tumors. For example, caspase-3 overexpression is present in neuroblastomas $^{8}$ and classical Hodgkin's disease, ${ }^{9,14}$ but reduced expression has been reported in prostatic carcinomas ${ }^{17}$ and renal cell carcinomas. ${ }^{15}$

In our study, caspase-3 overexpression was not associated with histology or prognosis. However, caspase-3 expression has been associated with histological type and grade of tumor, and with prognosis in other tumor types. Caspase-3 expression was present in classical Hodgkin's disease but not in nodular lymphocyte predominance Hodgkin's disease. ${ }^{9,14}$ Caspase-3 expression was reduced in moderately and poorly differentiated human prostate adenocarcinomas compared to well-differentiated adenocarcinomas and the normal prostate. ${ }^{17}$ High levels of caspase-3 mRNA expression in neuroblastomas were associated with favorable
Table 1 Caspase-3 overexpression status in HCCs compared to patient and tumor characteristics

\begin{tabular}{|c|c|c|c|c|}
\hline \multirow[t]{2}{*}{ Characteristic } & \multirow{2}{*}{$\begin{array}{c}\text { Total } \\
(\mathrm{n}=47) \\
\#\end{array}$} & \multicolumn{2}{|c|}{$\begin{array}{c}\text { Caspase-3 } \\
\text { Overexpression }\end{array}$} & \multirow[t]{2}{*}{ P-value } \\
\hline & & $\begin{array}{c}\text { Absent } \\
(\mathrm{n}=20) \\
\%(\#)\end{array}$ & $\begin{array}{c}\text { Present } \\
(\mathrm{n}=27) \\
\%(\#)\end{array}$ & \\
\hline Age (years) \pm s.d. & $61.6 \pm 13.4$ & $64.3 \pm 12.6$ & $59.6 \pm 13.8$ & $\mathrm{NS}^{\mathrm{a}}$ \\
\hline \multicolumn{5}{|l|}{ Gender } \\
\hline $\begin{array}{l}\text { Female } \\
\text { Male }\end{array}$ & $\begin{array}{l}19 \\
28\end{array}$ & $\begin{array}{l}37(7) \\
46(13)\end{array}$ & $\begin{array}{l}63(12) \\
54(15)\end{array}$ & NS \\
\hline \multicolumn{5}{|l|}{$\alpha$-fetoprotein } \\
\hline $\begin{array}{l}<40 \\
>40 \\
\text { Not available }\end{array}$ & $\begin{array}{l}12 \\
19 \\
16\end{array}$ & $\begin{array}{l}58(7) \\
16(3) \\
63(10)\end{array}$ & $\begin{array}{l}42(5) \\
84(16) \\
37(6)\end{array}$ & $0.01^{\mathrm{b}}$ \\
\hline \multicolumn{5}{|l|}{ Hepatitis } \\
\hline $\begin{array}{l}\text { Absent } \\
\text { Present }\end{array}$ & $\begin{array}{l}25 \\
22\end{array}$ & $\begin{array}{l}44(11) \\
41(9)^{\mathrm{c}}\end{array}$ & $\begin{array}{l}56(14) \\
59(13)^{d}\end{array}$ & NS \\
\hline \multicolumn{5}{|l|}{ Cirrhosis } \\
\hline $\begin{array}{l}\text { Absent } \\
\text { Present }\end{array}$ & $\begin{array}{l}24 \\
23\end{array}$ & $\begin{array}{l}37(9) \\
48(11)\end{array}$ & $\begin{array}{l}63(15) \\
52(12)\end{array}$ & NS \\
\hline \multicolumn{5}{|l|}{ Tumor stage } \\
\hline $\begin{array}{l}2 \\
3 \\
4\end{array}$ & $\begin{array}{l}16 \\
17 \\
14\end{array}$ & $\begin{array}{l}37(6) \\
47(8) \\
43(6)\end{array}$ & $\begin{array}{l}63(10) \\
53(9) \\
57(8)\end{array}$ & NS \\
\hline \multicolumn{5}{|l|}{ Vital status } \\
\hline $\begin{array}{l}\text { Alive } \\
\text { Dead }\end{array}$ & $\begin{array}{l}20 \\
27\end{array}$ & $\begin{array}{l}45(9) \\
41(11)\end{array}$ & $\begin{array}{l}55(11) \\
59(16)\end{array}$ & NS \\
\hline $\begin{array}{l}\text { Follow-up } \\
\text { (months) } \pm \text { s.d. }\end{array}$ & $29.0 \pm 29.1$ & $35.1 \pm 32.4$ & $24.6 \pm 26.0$ & $\mathrm{NS}^{\mathrm{e}}$ \\
\hline
\end{tabular}

${ }^{\mathrm{a}} \mathrm{NS}$, not significant.

${ }^{\mathrm{b}} \alpha$-fetoprotein $<40$ vs $>40$.

${ }^{\mathrm{C}}$ Hepatitis B viral infection $(n=3)$, hepatitis C viral infection $(n=2)$, alcoholic liver disease $(n=4)$, and hepatitis B viral infection and alcoholic liver disease $(n=1)$.

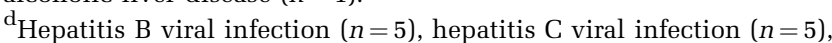
alcoholic liver disease $(n=3)$.

${ }^{\mathrm{e}}$ By Kaplan and Meier method, log-rank statistic.

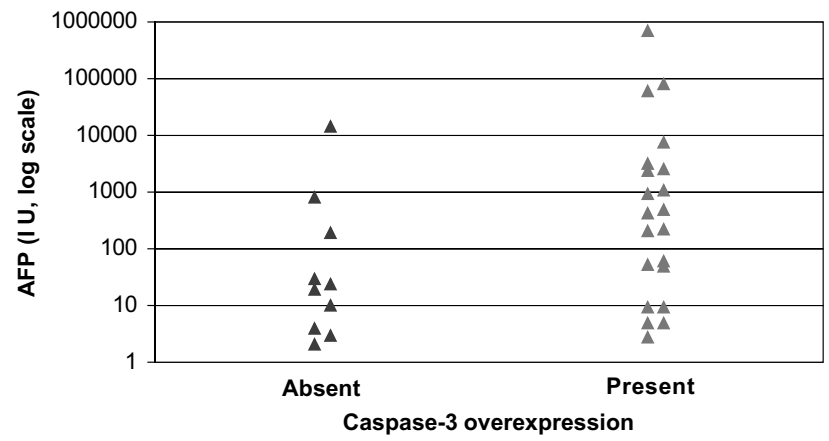

Figure 5 Serum AFP levels and human HCCs with and without caspase-3 overexpression by immunohistochemistry.

prognosis. ${ }^{8}$ In contrast, diffuse cytoplasmic staining in B-cell diffuse large cell lymphomas vs punctuate cellular localization of caspase-3 expression was 
associated with poor response to treatment and prognosis. ${ }^{16}$

In our study, a subset of HCCs had caspase-3 overexpression, but caspase-3 activation or increased apoptosis of tumor cells was not observed. In contrast, loss of caspase-3 expression is associated with resistance to apoptosis and resistance to therapy in a variety of tumors and cell lines. Loss of caspase-3 expression correlated with resistance to apoptosis in renal cell carcinomas. ${ }^{15}$ Resistance to apoptosis by a variety of apoptotic stimuli including chemotherapeutic agents due to lack of expression or activation of caspase-3 has been demonstrated in breast cancer, leukemia, and classic Hodgkin's disease cell lines. ${ }^{10,11,14,18}$ Resistance to cisplatin-, tamoxifen-, and ionizing radiation-induced apoptosis is dependent on caspase-3 in breast, lymphoblast, and HeLa cell lines. ${ }^{12,13,18,23,24}$

Cancers evade apoptosis by various mechanisms, including loss of Fas-receptor expression, overexpression of FasL by the cancer, loss or mutation of TGF $\beta$ receptor, and increased expression of inhibitor of apoptosis protein (IAP) family including c-IAP1, CIAP2, XIAP, and survivin. ${ }^{25-31}$ HCCs evade apoptosis by downregulating Fas possibly reducing the sensitivity of HCC to Fas-mediated apoptosis, by overexpressing FasL that can kill cytotoxic T-lymphocytes, ${ }^{27}$ and by overexpressing XIAP. ${ }^{32}$ Other inhibitors such as cellular FLICE/caspase-8inhibitory protein that inhibits caspase-8 activation are constitutively expressed in all human HCC cell lines and are expressed more in HCCs than in non-tumor liver. ${ }^{33}$

In our study, caspase-3 overexpression was associated with high serum levels of AFP. AFP is an oncoembryonal protein with cell growth regulating, differentiating, and immunosuppressive activities. AFP at low concentration is a growth factor for HCC cell lines, but at high concentration induces apoptosis in tumor cell lines in vitro. ${ }^{34,35}$ AFPinduced apoptosis is mediated by activation of caspase-3, and is independent of Fas/FasL or TNF signalling pathways. AFP-producing hepatoma cell lines have common gene-expression profile compared with AFP-negative hepatoma cell lines. ${ }^{36}$ Of note, all four hepatoma cell lines used in our study overexpressed caspase-3, including an AFP-negative cell line.

Alternatively, AFP and caspase-3 genes may share similar regulation during hepatocarcinogenesis. AFP is activated early in hepatogenesis, repressed postnatally, and can be reactivated during liver regeneration and in HCCs. The postnatal AFP repression is governed primarily by the promoter and repressor region of the gene that binds several nuclear factors (reviewed by Spear ${ }^{37}$ ), including hepatocyte nuclear factor $3,^{38}$ AT motif-binding factor $1,{ }^{39}$ and AFP regulators 1 and $2 .{ }^{40,41}$ It is possible that one of these or an additional regulatory factor is repressed in HCCs and results in overexpression of AFP and caspase-3.
In conclusion, caspase-3 was frequently overexpressed in HCCs and was associated with high serum levels of AFP. Caspase-3 overexpression may serve as a diagnostic and therapeutic marker for HCCs.

\section{References}

1 Reed JC. Mechanisms of apoptosis. Am J Pathol 2000;157:1415-1430.

2 Kanzler S, Galle PR. Apoptosis and the liver. Semin Cancer Biol 2000;10:173-184.

3 Fernandes-Alnemri T, Litwack G, Alnemri ES. CPP32, a novel human apoptotic protein with homology to Caenorhabditis elegans cell death protein Ced-3 and mammalian interlukin-1 $\beta$-converting enzyme. J Biol Chem 1994;269:30761-30764.

4 Nicholson DW, Ali A, Thornberry NA, et al. Identification and inhibition of the ICE/CED-3 protease necessary for mammalian apoptosis. Nature 1995;376:37-43.

5 Tiso N, Pallavicini A, Muraro T, et al. Chromosomal localization of the human genes, CPP32, Mch2, Mch3, and Ich-1, involved in cellular apoptosis. Biochem Biophys Res Comm 1996;225:983-989.

6 Nasir J, Theilmann JL, Chopra V, et al. Localization of the cell death genes CPP32 and Mch-2 to human chromosome 4q. Mamm Genome 1997;8:56-59.

7 Krajewska M, Wang H-G, Krajewski S, et al. Immunohistochemical analysis of in vivo patterns of expression of CPP32 (caspase-3), a cell death protease. Cancer Res 1997;57:1605-1613.

8 Nakagawara A, Nakamura Y, Ikeda H, et al. High levels of expression and nuclear localization of interleukin-1 $\beta$ converting enzyme (ICE) and CPP32 in favorable human neuroblastomas. Cancer Res 1997;57: 4578-4584.

9 Chhanabhai M, Krajewski S, Krajewska M, et al. Immunohistochemical analysis of interleukin-1 $\beta$-converting enzyme/Ced-3 family protease, CPP32/Yama/ Caspase-3, in Hodgkin's disease. Blood 1997;90: 2451-2455.

10 Li F, Srinivasan A, Wang Y, Armstrong RC, et al. Cellspecific induction of apoptosis by microinjection of cytochrome c: Bcl-xL has activity independent of cytochrome c release. J Biol Chem 1997;272:3029930305.

11 Los M, Herr I, Friesen C, et al. Cross-resistance of CD95- and drug-induced apoptosis as a consequence of deficient activation of caspases (ICE/Ced-3 proteases). Blood 1997;90:3118-3129.

12 Eichholtz-Wirth H, Stoetzer O, Marx K. Reduced expression of the ICE-related protease CPP32 is associated with radiation-induced cisplatin resistance in HeLa cells. Br J Cancer 1997;76:1322-1327.

$13 \mathrm{Yu} \mathrm{Y,} \mathrm{Little} \mathrm{JB.} \mathrm{p53} \mathrm{is} \mathrm{involved} \mathrm{in} \mathrm{but} \mathrm{not} \mathrm{required} \mathrm{for}$ ionizing radiation-induced caspase-3 activation and apoptosis in human lymphoblast cell lines. Cancer Res 1998;58:4277-4281.

14 Izban KF, Wrone-Smith T, Hsi ED, et al. Characterization of the interleukin- $1 \beta$-converting enzyme/Ced-3family protease, caspase-3/CPP32, in Hodgkin's disease: lack of caspase-3 expression in nodular lymphocyte predominance Hodgkin's disease. Am J Pathol 1999;154:1439-1447. 
15 Kolenko V, Uzzo RG, Bukowski R, et al. Dead or dying: necrosis versus apoptosis in caspase-deficient human renal cell carcinoma. Cancer Res 1999;59: 2838-2842.

16 Donoghue S, Baden HS, Lauder I, et al. Immunohistochemical localization of caspase-3 correlates with clinical outcome in B-cell diffuse large cell lymphoma. Cancer Res 1999;59:5386-5391.

17 Winter RN, Kramer A, Borkowski A, et al. Loss of caspase-1 and caspase-3 protein expression in human prostate cancer. Cancer Res 2001;61:1227-1232.

18 Devarajan E, Sahin AA, Chen JS, et al. Down-regulation of caspase-3 in breast cancer: a possible mechanism for chemoresistance. Oncogene 2002;21:8843-8851.

19 Fujikawa K, Shiraki K, Sugimoto K, et al. Reduced expression of ICE/caspase1 and CPP32/caspase3 in human hepatocellular carcinoma. Anticancer Res 2000;20:1927-1932.

20 Shen L, Ahuja N, Shen Y, et al. DNA methylation and environmental exposures in human hepatocellular carcinoma. J Natl Cancer Inst 2002;94:755-761.

21 Rashid A, Wu T-Z, Huang C-C, et al. Mitrochondrial proteins that regulate apoptosis and necrosis are induced in mouse fatty liver. Hepatology 1999; 29:1131-1138.

22 Kaplan EL, Meier P. Nonparameteric estimation from incomplete observations. J Am Stat Assoc 1958;53: 457-481.

23 Blanc C, Deveraux QL, Krajewski S, et al. Caspase-3 is essential for procaspase-9 processing and cisplatininduced apoptosis of MCF-7 breast cancer cells. Cancer Res 2000;60:4386-4390.

24 Mandlekar S, Yu R, Tan T-H, et al. Activation of caspase-3 and c-Jun $\mathrm{NH}_{2}$-terminal kinase-1 signaling pathways in tamoxifen-induced apoptosis of human breast cancer cell lines. Cancer Res 2000;60: 5995-6000

25 Hahne M, Rimoldi D, Schroter M, et al. Melanoma cell expression of Fas (Apo-1/CD-95) ligand: implications for tumor immune escape. Science 1996;274: 1363-1366.

26 Moller P, Koretz K, Leithauser F, et al. Expression of APO-1 (CD95), a member of the NGF/TNF receptor superfamily, in normal and neoplastic colon epithelium. Int J Cancer 1994;57:371-377.

27 Strand S, Hofmann WJ, Hug $\mathrm{H}$, et al. Lymphocyte apoptosis induced by CD95 (APO-1/Fas) ligand-expressing tumor cells-a mechanism of immune evasion? Nat Med 1996;2:1361-1366.

28 Kiso S, Kawata S, Tamura S, et al. Alteration in growth regulation of hepatocytes in primary culture obtained from cirrhotic rat: poor response to transforming groth factor-beta 1 and interferons. Hepatology 1994;20: 1303-1308.
29 Asselin E, Mills GB, Tsang BK. XIAP regulates Akt activity and caspase-3-dependent cleavage during cisplatin-induced apoptosis in human ovarian epithelial cancer cells. Cancer Res 2001;61:1862-1868.

30 Zhang XD, Zhang XY, Gray CP, et al. Tumor necrosis factor-related apoptosis-inducing ligand-induced apoptosis of human melanoma is regulated by Smac/ DIABLO release from mitochondria. Cancer Res 2001;61:7339-7348.

31 McKay TR, Bell S, Tenev T, et al. Procaspase 3 expression in ovarian carcinoma cells increases survivin transcription which can be countered with a dominant-negative mutant, survivan T34A; a combination gene therapy strategy. Oncogene 2003;22: 3539-3547.

32 Shiraki K, Sugimoto K, Yamanaka Y, et al. Overexpression of X-linked inhibitor of apoptosis in human hepatocellular carcinoma. Int J Mol Med 2003;12: 705-708.

33 Okano H, Shiraki K, Inoue H, et al. Cellular FLICE/ caspase-8-inhibitory protein as a principal regulator of cell death and survival in human hepatocellular carcinoma. Lab Invest 2003;83:1033-1043.

34 Dudich IV. Induction of apoptosis in human hepatoma cells by alpha-fetoprotein. Tumour Biol 1997;18: 261-273.

35 Dudich E, Samenkova L, Dudich I, et al. Alphafetoprotein causes apoptosis in tumor cells via a pathway independent of CD95, TNFR1 and TNFR2 through activation of caspase-3-like proteases. Eur J Biochem 1999;266:750-761.

36 Kawai HF, Kaneko S, Honda M, et al. fetoproteinproducing hepatoma cell lines share common expression profiles of genes in various categories demonstrated by cDNA microarray analysis. Hepatology 2001;33:676-691.

37 Spear BT. Alpha-fetoprotein gene regulation: lessons from transgenic mice. Semin Cancer Biol 1999;9: 109-116.

38 Crowe AJ, Sang L, Li KK, et al. Hepatocyte nuclear factor 3 relieves chromatin-mediated repression of the $\alpha$-fetoprotein gene. J Biol Chem 1999;274: 25113-25120.

39 Ninomiya T, Mihara K, Fushimi K, et al. Regulation of the $\alpha$-fetoprotein gene by the isoforms of ATBF1 transcription factor in human hepatoma. Hepatology 2002;35:82-87.

40 Peyton DK, Huang M-C, Giglia MA, et al. The alphafetoprotein promoter is the target of Afr1-mediated postnatal repression. Genomics 2000;63:173-180.

41 Jin DK, Vacher J, Feuerman MH. $\alpha$-Fetoprotein gene sequences mediating Afr2 regulation during liver regeneration. Proc Natl Acad Sci USA 1998;95: 8767-8772. 